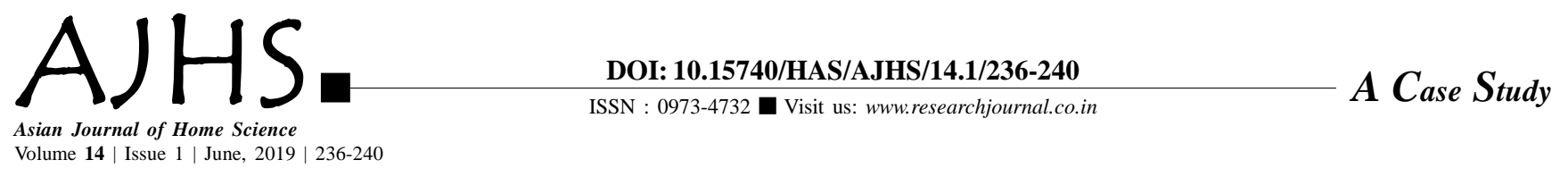

\title{
Herbal medicines -a safe cure for common health ailments
}

\author{
Apoorva Gupta and Meenu Srivastava
}

Received: 01.03.2019; Accepted: 28.05.2019

See end of the paper for authors' affiliations

\section{Apoorva Gupta}

Department of Textiles and

Apparel Designing, College of

Community and Applied Sciences,

Maharana Pratap University of

Agriculture and Technology,

Udaipur (Rajasthan) India
-ABSTRACT : Now-a-days, attention is being focused on the investigation of the efficacy of plant in the traditional medicine because they are cheap and have little side effects. Synthetic preservatives, which have been used in foods for decades, may lead to negative health consequences (Shadia et al., 2016). Increasing numbers of people have been choosing herbal medicines or products to improve their health conditions, either alone or in combination with others. Herbs are staging a comeback and herbal "renaissance" occurs all over the world. According to the World Health Organization, 75 per cent of the world's populations are using herbs for basic healthcare needs. Since the dawn of mankind, in fact, the use of herbs/plants has offered an effective medicine for the treatment of illnesses (Si-Yuan Pan et al., 2014). The probability of a real and substantial interaction between the therapeutic agents originating from different medical paradigms is likewise expanding. Whilst most of the herb-drug interactions are undoubtedly minor, benign and harmless, there are reports of more serious interactions. Possible reasons for specific herb-drug interactions are examined, particularly from the pharmacokinetic and pharmacodynamics perspectives (Media Centre Traditional Medicine, 2013).This paper aims to provide a review of benefits of herbal medicines and to cure common health ailments, herbal medicines in terms of their significant contribution to the health promotion for health ailments in present scenario.

KEY WORDS: Health, Ailments, Health care, Herbal, Medicines, Traditional remedies

- HOW TO CITE THIS PAPER : Gupta, Apoorva and Srivastava, Meenu (2019). Herbal medicines -a safe cure for common health ailments. Asian J. Home Sci., 14 (1) : 236-240, DOI: 10.15740/HAS/AJHS/14.1/ 236-240. Copyright@ 2019: Hind Agri-Horticultural Society. 